\title{
The relationship between diet, energy balance and fertility in men
}

\author{
Edyta Suliga ${ }^{1}$ and Stanisław Gtuszek ${ }^{2}$ \\ 1 Department of Nutrition and Dietetics, Institute of Public Health, Faculty of Medicine and Health Sciences, \\ Jan Kochanowski University, Kielce, Poland \\ 2 Department of Surgery and Surgical Nursing with the Scientific Research Laboratory, Institute of Medical Sciences, \\ Jan Kochanowski University, Kielce, Poland
}

Received: May 26, 2018; Accepted: October 19, 2018

\begin{abstract}
Research conducted in recent years provides more and more evidence that diet can have a significant impact on male fertility. The aim of the study was to analyze the relationship between diet, energy balance and fertility in men. A comprehensive literature search of published studies in various languages, was carried out in electronic databases. The direct analysis included 96 works published between 2008 and 2018, including 12 randomized controlled trials and 23 systematic reviews and meta-analyses. A strong adherence to a healthy dietary pattern is positively correlated with total sperm count, progressive motility and total motile sperm count (all $p<0.05$ ). However, attention is drawn to the fact that foods that are considered "healthy" can sometimes contain a significant amount of pollution, which negatively affect the semen parameters. An adequate intake of antioxidants or their supplementation have been quite effective in the prevention and treatment of male infertility. The improvement of pregnancy rate after antioxidant therapy ranged in various studies from $11 \%$ to $41 \%$. An important problem, however, may be choosing the right dose of the supplement or finding an appropriate combination of antioxidants that may be more effective than any single antioxidant. The normalization of men's body weight is beneficial for the quality of sperm and the concentration of male reproductive hormones. Further, long-term studies require the assessment of the impact of drastic weight loss after bariatric surgery on male fertility.
\end{abstract}

Keywords: male fertility, dietary patterns, nutrients, antioxidants, Body Mass Index

\section{Introduction}

The prevalence of infertility among couples of reproductive age ranges, according to various sources, from $8 \%$ to $25 \%$ [1-3]. Male infertility is the only cause of infertility in $20-30 \%$ of cases and a factor contributing to infertility in $50 \%$ of all infertility cases [4]. The assessment of male fertility usually includes medical examination and comparison with the reference values of the following semen parameters: volume, total sperm count, concentration, motility and morphology (Table 1) [5]. Low sperm count and/or quality is present in $90 \%$ of couples with fertility problems [6]. In the assessment of fertility, the concentrations of male reproductive hormones are also analyzed. More recently, the molecular composition of sperm cells, assessed by evaluating the degree of DNA fragmentation or oxidative stress [7] has been increasingly taken into account. Several studies use the DNA fragmentation index (DFI) as an indicator of pregnancy success. According to Evenson and Wixon, DFI ranges from 3 to $5 \%$ in healthy men, while a DFI of $\geq$ $30 \%$ is associated with reduced fertility [8]. Currently defined genetic factors, including both chromosomal aberrations and monogenic changes, account for only about $10-15 \%$ of cases of male infertility [9]. The cause for fertility problems may also be environmental factors. The aim of the study was to analyze the relationship between diet, energy balance and fertility rates in men.

\section{Strategy of literature search}

A comprehensive literature search of published studies in various languages, was carried out in electronic databases, including: PubMed, Cochrane Central Register of Controlled Trials (CENTRAL), Cochrane Database of Systematic Review and Google Scholar. Randomized controlled trials, observational and qualitative studies published between 2008 and 2018 (up to and including March) were included. The following keywords related to male infertility, diet, nutrients and their combinations (made by applying operators AND and OR) were used in the search: 'male infertility', 'sperm quality', 'idiopathic 
Table 1. Reference values of the World Health Organization for human semen parameters (WHO 2010).

\begin{tabular}{ll}
\hline Semen parameter & $\begin{array}{l}\text { Reference limit } \\
\text { (95\% confidence intervals) }\end{array}$ \\
\hline Semen volume & $1.5 \mathrm{ml}(1.4-1.7)$ \\
Total sperm count & 39 million per ejaculate (33-46) \\
Sperm concentration & 15 million per ml (12-16) \\
Vitality & $58 \%$ live (55-63) \\
Progressive motility & $32 \%(31-34)$ \\
Total (progressive + nonprogressive) & $40 \%(38-42)$ \\
motility & \\
Morphologically normal forms & $4.0 \%(3.0-4.0)$ \\
\hline
\end{tabular}

oligozoospermia', 'astenoazospermia', 'oligoastenoteratozoospermia', 'sperm DNA damage', 'nutritional status', 'BMI', 'obesity', 'diet', 'nutrition', dietary pattern', 'food', 'nutrient', 'fatty acids', 'antioxidant', 'supplementation', 'vitamin C', 'vitamin E', vitamin A', 'folate', 'zinc', 'selenium', 'L-carnitine', 'glutathione', 'coenzyme Q10', 'N-acetylcysteine', 'lycopene'. Reference lists of studies extracted from the primary electronic search were used to identify additional relevant studies.

\section{Dietary patterns and food groups}

The analysis of dietary patterns is increasingly used to assess the relationship between diet and the risk of many diseases and health problems [10]. This approach allows one to achieve a more accurate description of a diet and a more comprehensive illustration of its complexity when compared to studies about the intake of isolated nutrients. Dietary patterns also accurately reflect global changes in dietary behaviors in different populations. Studies on the association between dietary patterns and semen quality among men are sparse (Table 2).

The results of the meta-analysis of observational studies confirm that male adherence to a healthy diet could improve semen quality and fecundability rates [18]. Oostingh et al. noted in their prospective study that sperm concentration, total sperm count, progressive motility and total motile sperm count were all positively associated with a strong adherence to the healthy dietary pattern, especially in men with poor semen quality [14]. Analyzing semen quality parameters in male partners of couples attempting fertility, it was found that men in the lowest adherence to the Mediterranean diet score had approximately a 2.6 times higher likelihood of having abnormal sperm concentration, total sperm count and motility, compared to men in the highest adherence of the score [19]. The meta-analysis of observational studies, that has been conducted recently showed, that individuals in the lowest adherence to the healthy dietary pattern had a significantly lower level of sperm concentration [20]. No significant association was seen between dietary patterns and other semen quality.

The associations between the intake of specific food groups and the semen quality have been analyzed in many studies. There was an inverse relation between processed red meat intake and total sperm count among young men [21]. The risk of asthenozoospermia was also significantly higher in the highest tertiles of processed meat and sweets intake [22]. Fish consumption was related to a higher sperm count and percentage of morphologically normal sperm. The mean total sperm count increased from 102 million in the lowest to 168 million sperm in the highest quartile of fish intake [23]. In increasing quartiles of fish consumption, the percentage of morphologically normal sperm was higher too. The authors found that consuming fish may have a positive impact on semen parameters, particularly when consumed instead of processed red meats. The results of an analysis conducted by Mínguez-Alarcón et al. demonstrated, however, an exposure to mercury $(\mathrm{Hg})$ through fish intake [24]. Men in the highest quartile of high mercury levels had a sperm concentration higher by $50 \%$, a total sperm count higher by $46 \%$ and progressive motility higher by $31 \%$, compared to men in the lowest quartile. These associations were stronger in those men who consumed more fish than the median in the studied group.

In a cohort of young, physically active men, dairy food intake was inversely related to sperm morphology and progressive motility [25]. This association was stronger for fullfat dairy foods. A study conducted in Iran demonstrated that the odds of asthenozoospermia were significantly lower with the intake of skim milk, and higher with an intake of total dairy products [22]. It is assumed that dairy food intake has been related to decreased secretion of LH, FSH and testosterone [26]. Moreover, dairy often includes environmental contaminants (pesticides and chlorinated pollutants) [27]. These contaminants have been associated with lower sperm quality and may be responsible for the observed relationship [27-31].

Chiu et al. found that total fruit and vegetable consumption was unrelated to semen quality parameters [31, 32]. The intake of fruit and vegetables with high pesticide residues was unrelated to semen quality in healthy young men, whereas low-to-moderate pesticide residues was associated with a higher sperm concentration and total sperm count [32]. The consumption of high pesticide - residue on fruits and vegetables was inversely associated with a lower percentage of morphologically normal sperm, total sperm count and ejaculate volume among men attending a fertility clinic [31]. The intake of low-to-moderate pesticide- residue produce was positively related to sperm morphology. 
Table 2. Main characteristics of studies on relationship between dietary patterns and fertility parameters in men.

\begin{tabular}{|c|c|c|c|}
\hline Reference & Participants & Semen quality parameters & Dietary pattern (DP) \\
\hline $\begin{array}{l}\text { Vujkovic } \\
\text { et al. [11] }\end{array}$ & $\begin{array}{l}\text { Men of subfertile } \\
\text { couples undergoing } \\
\text { in vitro fertilization } \\
\text { treatment }(\mathrm{N}=161)\end{array}$ & $\begin{array}{l}\text { sperm volume, } \\
\text { concentration, motility, } \\
\text { morphology and DNA } \\
\text { fragmentation index (DFI) }\end{array}$ & $\begin{array}{l}\text { The Health Conscious DP } \\
\text { characterized by high intake of } \\
\text { fruits, vegetables, fish and } \\
\text { whole grains. The Traditional } \\
\text { Dutch DP characterized by high } \\
\text { intakes of meat, potatoes and } \\
\text { whole grains and low intakes of } \\
\text { beverages and sweets. }\end{array}$ \\
\hline $\begin{array}{l}\text { Gaskins } \\
\text { et al. [12] }\end{array}$ & $\begin{array}{l}\text { Men aged } 18-22 \\
\text { (participants in the } \\
\text { Rochester Young } \\
\text { Men's Study) ( } N=188)\end{array}$ & $\begin{array}{l}\text { sperm concentration, } \\
\text { progressive motility and } \\
\text { morphology }\end{array}$ & $\begin{array}{l}\text { The Western DP was } \\
\text { characterized by high intake of } \\
\text { red and processed meat, } \\
\text { refined grains, pizza, snacks, } \\
\text { high-energy drinks and sweets. } \\
\text { The Prudent DP was } \\
\text { characterized by high intake of } \\
\text { fish, chicken, fruit, vegetables, } \\
\text { legumes and whole grains. }\end{array}$ \\
\hline
\end{tabular}

\section{Jurewicz Men who attended the et al. [13] infertility clinic for diagnostic purposes and who had normal semen concentration of 20 to $300 \mathrm{mln} / \mathrm{ml}$ or slight oligozoospermia (semen concentration of $15-20 \mathrm{mln} / \mathrm{ml})(\mathrm{N}=336)$}

Oostingh Men aged on average et al. [14] $35( \pm 6$ SD) years old with $\mathrm{BMI}$ of $26.4 \pm 4 \mathrm{~kg} / \mathrm{m}^{2}$

ejaculate volume, sperm concentration, total sperm count, progressive motility, immotile sperm, and total motile sperm count (TMSC)

motility, morphology, sperm chromatin structure (DNA fragmentation index - DFI), high DNA stainability; the level of reproductive hormones$$
\text { motile sperm count (TMSC) }
$$

The Prudent DP (high intakes of fish, chicken, fruit, cruciferous vegetables, tomatoes, leafy green vegetables, legumes, and whole grains). The Western DP (high intakes of red and processed meat, butter, highfat dairy, refined grains, pizza, snacks, high energy drinks, mayonnaise, and sweets). The other men were classified as the Mixed DP

The Healthy DP (high intakes of cereals, fruits, legumes, vegetables, and olive oil). The Unhealthy DP (high intakes of dairy, margarines, mayonnaise, sauces, snacks and sweets).

sperm concentration (SC), normal sperm morphology (NSM), total sperm motility (TSM), progressive motility (PRM)
Conclusion/key findings

An inverse association was demonstrated between the Health Conscious DP and DFI $(\beta=-2.81 ; p=0.05)$. The Traditional Dutch DP was positively correlated with sperm concentration ( $\beta=13.25$; $p=0.01$.

Men in the highest quartile of the Prudent DP had $11.3 \%$ higher \% progressively motile sperm compared with men in the lowest quartile (P-trend $=0.04)$. The Prudent DP was unrelated to sperm concentration and morphology. The Western DP was not associated with any semen parameter.

Higher consumption of a Prudent DP was associated with higher sperm concentration $(p=0.05)$ and higher level of testosterone ( $p=0.03$ ). Sperm chromatin structure was inversely related to higher consumption of a Prudent DP $(p=0.05)$.

Sperm concentration $(\beta=0.278 ; p<0.05)$, total sperm count ( $\beta=1.369$; $p<0.05)$, progressive motility $(\beta=4.305 ; p<0.05)$, and TMSC $(\beta=0.319 ; p<0.05)$ were positively associated with the Healthy DP. No significant associations with strong adherence to the Unhealthy DP.

A high intake of a Western DP resulted in statistically linear declines of SC $(p<0.001)$ and NSM ( $p<0.001)$. Similarly, a greater intake of High sweet snacks \& sugar-sweetened drinks" was associated with a lower SC ( $p=0.001)$. Increased intake of a High-carbohydrate DP was related to higher prevalence of abnormal TSM $(p=0.012)$ and PRM ( $p=$ 0.025). A greater intake of a High-sodium DP was correlated with an elevated prevalence of abnormal NSM ( $p=0.035)$. 
Table 2. (Continued)

\begin{tabular}{lll}
\hline Reference & Participants & Semen quality parameters \\
\hline Eslamian & 107 incident & Asthenozoospermia risk - \\
et al. [16] & asthenozoospermic men & semen quality data were \\
& and 235 age-matched & analyzed according to the \\
& controls & fifth edition of the World \\
& Health Organization \\
& guidelines
\end{tabular}

Cutillas-Tolín et al. [17]

\begin{abstract}
Healthy male university students aged 18-23 years $(N=215)$
\end{abstract}

Total sperm count, semen volume, concentration, morphologically normal sperm (\%), total motile sperm, testicular volume, the level of reproductive hormones

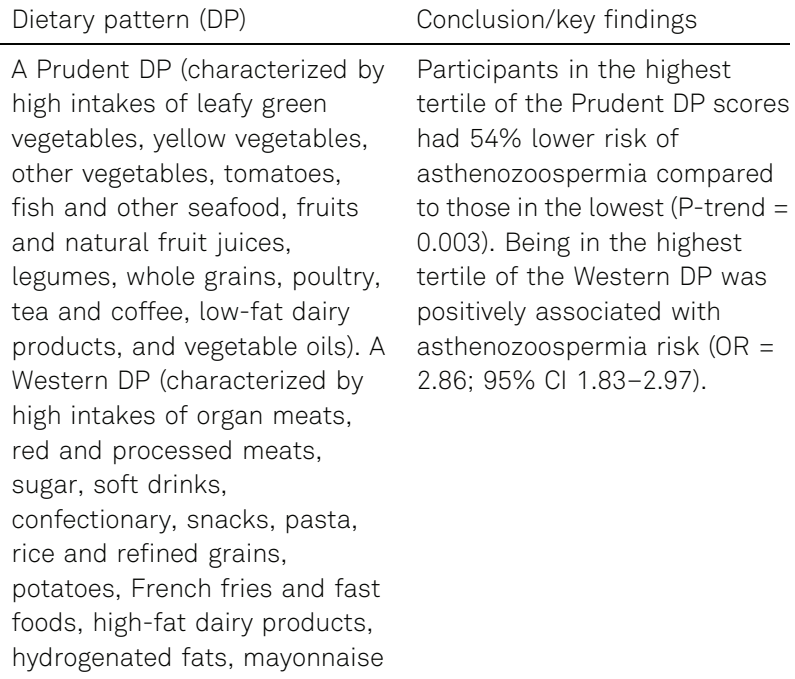

Conclusion/key findings

Participants in the highest tertile of the Prudent DP scores had $54 \%$ lower risk of asthenozoospermia compared to those in the lowest (P-trend = 0.003). Being in the highest tertile of the Western DP was positively associated with asthenozoospermia risk (OR = 2.86; 95\% Cl 1.83-2.97).

The Mediterranean DP was positively associated with total sperm count (P-trend $=0.040$ ). The Western DP was positively related to the percentage of morphologically normal sperm (P-trend $=0.008$ ). An inverse association was found between adherence to the Western DP and sperm concentration among overweight or obese men (P-trend $=0.040)$.
Robbins et al. found that in a group of healthy young men, $75 \mathrm{~g}$ of walnuts/day added for 12 weeks to a Western-style diet improved sperm vitality, motility, and morphology [33]. In a cross-sectional study, it was found that the intake of soy foods was inversely proportional to the concentration of sperm [34]. It was observed that these compounds were stronger among men with normal or high sperm concentrations than in men with low sperm concentration and in men with overweight and obesity, compared to those with normal weight. The authors suggest that the phytoestrogens contained in soy may affect spermatogenesis by binding membrane estrogen receptors and in this way they can induce transcriptional activity to the same extent as estradiol. The study did not show the effect of soy food intake on sperm motility, morphology or ejaculate volume. Beaton et al. showed that consumption of soy protein of low or high isoflavone content had no negative effect on sperm parameters among healthy adult males [35]. The meta-analysis carried out in 2010 did not confirm the relationship between the consumption of soy foods and isoflavone supplements by men and measurements of bioavailable testosterone concentrations [36].
Some studies included the influence of saffron, commercially used as a food spice, on the quality of sperm. In infertile men receiving $50 \mathrm{mg}$ of saffron for 3 months, three times a week, an improvement in sperm morphology and motility was found, but no increase in sperm count was noted [37]. In another randomized trial, one group of men with idiopathic oligoasthenoteratozoospermia was given $60 \mathrm{mg}$ /day saffron for 26 weeks, and a placebo in the second group. However, there was no significant improvement in semen parameters and total seminal plasma antioxidant capacity [38].

An analysis of scientific studies show that there are specific dietary patterns in different populations. The synergistic effect of the various combinations of vegetables, fruits and fish consumed, which are the main components of 'healthy' or 'prudent' dietary patterns, was associated with better sperm parameters in men in almost all the studies. A high intake of red and processed meat was associated with poor semen quality in different populations. The results of research on the influence of individual food groups confirm the main observations resulting from the analysis of the impact of dietary patterns on semen quality. 


\section{Nutrients}

Many studies support the hypothesis that specific nutrients (total fat, saturated fatty acids, polyunsaturated fatty acids, trans fatty acids, vitamin D and antioxidants) can affect semen quality. Men with poor semen quality had a significantly higher intake of proteins and total fat, and a lower intake of carbohydrates and fiber than control subjects [39]. Attaman et al. noted that a high total fat intake was negatively related to total sperm count and sperm concentration [40]. The authors also found that levels of saturated fatty acids in sperm were negatively related to sperm concentration. Jensen et al. detected, on a sample of 701 young Danish men, a dose-response association between the increased intake of saturated fat and total sperm count and sperm concentration [41]. Men in the highest quartile of saturated fat intake had a $41 \%$ lower total sperm count and a $38 \%$ lower sperm concentration than the men in the lowest quartile. Additionally, the percentage of spermatozoa with a normal morphology was lower among men with a high percentage of energy from monounsaturated fat. In a study conducted in the Iranian population, chances of having normal semen volume increased by $27.5 \%$ for each additional $1 \mathrm{~g}$ of fat consumed, and with each additional 1 $\mathrm{g}$ of saturated fat in the diet, the chance of achieving a normal sperm volume decreased by $38 \%$ [42].

Dietary supplementation of omega-3 fatty acids for 32 weeks increased the total sperm cell count, sperm cell concentration and the total percentage of sperm with normal morphology [43]. In one study a supplementation with nutritional levels of DHA and EPA, carried out for 3 months, in idiopathic infertile patients, did not significantly change the conventional sperm parameters [44]. Semen volume was also higher among men with a high intake of $n-3$ polyunsaturated fatty acids [41]. A higher intake of n-3 fatty acids was also related to a more favorable sperm morphology [40]. Kolahdooz et al. found that black cumin seed oil (Nigella sativa L) may be able to improve the sperm quality of infertile men [45]. They showed that sperm count, volume, motility and morphology were significantly improved in the N. sativa oil treated group compared with the placebo group after 2 months. In the authors' opinion the beneficial influence of the oil on the quality of the sperm can be contributed, to a large extent, to the influence of dihomo-gamma-linolenic acid (20:3n-6).

Trans fatty acid consumption was inversely related to total sperm count in young healthy men [46]. The authors also found a positive association between stearic acid intake and sperm motility and an inverse association between cholesterol intake and ejaculate volume. An adequate intake of certain fatty acids affects semen quality and is necessary for normal spermatogenesis. Polyunsaturated fatty acids are structural components of cell membranes of spermatozoa and they contribute to maintaining their fluidity and permeability. The excessive consumption of saturated fats and trans fatty acids from unhealthy diets may lead to their accumulation in testicular cells. This may affect the fatty acid composition of the plasma membrane and the process of spermatogenesis, inhibit testosterone production and induce Leydig cells apoptosis [47-50].

Data on the effect of fatty acid intake on the concentration of reproductive hormones in men are scarce. In a population of young healthy Spanish men, the intake of monounsaturated fatty acids was inversely associated with serum blood levels of total and calculated free testosterone [51]. A positive association was also observed between polyunsaturated fatty acid intake (particularly of n-6 fatty acids) and luteinizing hormone (LH) concentrations [51]. Chavarro et al. had reported that men in the highest quartile of trans fatty acid intake had testosterone levels lowered by 15\% [52]. Minguez-Alarcón et al also confirmed that the intake of trans fatty acids was associated with lower total testosterone concentration and calculated free testosterone concentration [51].

Numerous studies have shown that vitamin D may be a regulator of fertility and reproductive function in individuals [53]. It was also found that the presence of a vitamin D receptor and/or the vitamin D metabolizing enzymes can be treated as a predictive marker for semen quality [54]. Most of the published papers analyze the relationships between the vitamin D status in the body and the quality of the semen, and only a few of them studied the effect of supplementation on fertility indicators. After 3 months of treatment with oral vitamin D $200 \mathrm{IU} /$ day, in infertile men with idiopathic oligoasthenozoospermia, the improvement of semen quality was observed, especially the progressive sperm motility [55]. A recent randomized study in which the effect of supplementation with vitamin D and calcium on the fertility of men with a known vitamin D deficiency was analyzed, showed that supplementation did not affect the quality of the semen or the rate of live births. However, treatment with vitamin D resulted in a slight increase in semen production and a higher number of live births in couples, in which the male had oligozoospermia compared to men in the placebo group [56]. Lerchbaum et al. studied the effect of vitamin D supplementation on the concentration of sex hormones in healthy men [57]. They found that the administration of 20,000 IU/week of vitamin $\mathrm{D}_{3}$ for 12 weeks had no effect on the total testosterone levels. Conversely, Canguven et al. found that vitamin $\mathrm{D}$ treatment improved testosterone levels and erectile functions at the end of the 12 months' follow-up [58]. Minguez-Alarcon et al. did not find, however, a correlation between vitamin $\mathrm{D}$ consumption and sperm parameters [59]. 
It appears plausible that certain nutrients may have mediated the effects of dietary patterns and food groups on semen quality. High intake of fats, especially saturated ones, and trans-fatty acids was negatively related to sperm count and concentration. However, the positive effect of polyunsaturated fatty acids, especially n-3 fatty acids on total sperm count, sperm concentration and a more favorable sperm morphology has been noted. Very few papers have been published in which the associations between consumption of proteins as well as carbohydrates, and the quality of semen were analyzed. It is not possible to formulate any conclusions regarding these nutrients. The relationship between the intake of vitamin D supplements and men's reproductive health is for the time being ambiguous and requires further research.

\section{Antioxidants}

Free radical processes (related to the formation of free radicals) play an important role in the development of infertility in men. Sperm cytoplasm contains small amounts of enzymes that capture free radicals, which is why they have quite a limited antioxidant protection. In addition, they are sensitive to the detrimental effect of oxidative stress due to the high content of polyunsaturated fatty acids in the cell membrane. Semen pathology induced by oxidative stress involves damage to cell membranes and DNA, leading to asthenozoospermia (reduced number of motile sperm in semen), necrosiscommia (lack of viability of spermatozoa in the ejaculate), and DNA fragmentation [60]. Tremellen reports that $30 \%$ to $80 \%$ of cases of reduced male fertility result from the harmful effects of oxidative stress on sperm [61]. The antioxidant system that protects sperm from free radicals, consists of both the enzyme complex, as well as non-enzymatic substances, which include vitamins $\mathrm{C}, \mathrm{A}$, $\mathrm{E}, \mathrm{B}$ vitamins, coenzyme $\mathrm{Q}_{10}$, L-carnitine, glutathione and micronutrients such as zinc, selenium, and copper [62]. The influence of lycopene and N-acetyl-cysteine on the quality of sperm is also of interest. In some studies, the relationships between single antioxidants and fertility rates were analyzed, whereas recently the influence of various combinations of many nutrients has increasingly been studied.

In a meta-analysis published in 2014, it was stated that there is little evidence suggesting that antioxidant supplementation in subfertile males may improve live birth rates for couples attending fertility clinics [63]. Many individual interventional studies conducted among subfertile/ infertile men showed, however, a positive effect of supplementation on sperm parameters. In the group of subfertile men who received 2 capsules with zinc sulfate for 4 months (440 $\mathrm{mg}$ total), the mean value of semen volume, the percentage and total normal sperm count and progressive sperm motility were significantly increased [64]. It was also found that zinc supplementation restored the proper range of oxygen sensitivity and catalase activity in the semen of men with asthenozoospermia [65]. Ajina et al. noted that antioxidant treatment based on in vitro supplementation of zinc, increased values of the antioxidant status index in infertile men, however, it did not prevent sperm lipid peroxidation [66]. In one study of 690 infertile men with idiopathic asthenoteratospermia, simultaneous supplementation with selenium, at a dose of $200 \mu \mathrm{g}$ per day and vitamin $\mathrm{E}$ at a dose of $400 \mathrm{IU}$ per day, for at least 100 days was used [67]. In 52.6\% of participants, an improvement in sperm motility and/or sperm morphology was observed. In addition, as many as $10.8 \%$ of partners of those men became pregnant.

In general, the human trials showed that an intake of 4-8 mg of lycopene supplements a day for 3-12 months, improve sperm parameters and is sufficient to treat male infertility [68]. Devaraj et al. found that a daily dose of $30 \mathrm{mg}$ of lycopene was required for a $9 \%$ decrease in DNA damage [69]. In a study conducted by Safarinejad, 287 infertile men with idiopathic oligoasthenoteratozoospermia were treated with coenzyme $\mathrm{Q}_{10}$, with an oral dose of $300 \mathrm{mg}$ twice a day [70]. After 12 months of therapy, a significant improvement of mean sperm concentration (of $113.7 \%$ ), sperm progressive motility (of 104.8\%), and sperm with normal morphology (of 78.9\%) was observed. The results of the meta-analysis, carried out by Lafuente et al., confirmed that coenzyme $\mathrm{Q}_{10}$ improves sperm parameters, however, there was no increase in live births or pregnancy rates [71]. N-acetyl-cysteine, administered orally in an amount of $600 \mathrm{mg} / \mathrm{d}$ for 3 months, had significant improving effects on the volume, motility, and viscosity of semen, and the serum total antioxidant capacity [72]. All semen parameters significantly improved with $\mathrm{N}$-acetyl-cysteine and selenium treatment. There was also a decrease in the concentration of follicle-stimulating hormone and an increase in serum concentration of testosterone [73].

In the group of 50 infertile men with established oxidative stress, treatment lasting 3 months was conducted, consisting of the administration of vitamin C $(100 \mathrm{mg})$, E (400 IU), folic acid $(0.5 \mathrm{mg})$, zinc $(25 \mathrm{mg})$, selenium (26 ug) and garlic (1 mg). The study showed that the therapy applied resulted in a significant improvement of sperm DNA and protamine packaging integrity. In addition, a reduction in apoptosis and seminal production of reactive oxygen species was observed. There were no significant changes in the concentration of male reproductive hormones, as well as concentration, sperm motility and morphology [74]. Lipovac et al. showed that the administration of a combination of eight micronutrients (440 mg of L-carnitine $+250 \mathrm{mg}$ of L-arginine $+120 \mathrm{mg}$ 
of vitamin $\mathrm{E}+800 \mu \mathrm{g}$ of folic acid $+80 \mathrm{mg}$ of glutathione + $15 \mathrm{mg}$ of coenzyme Q10 $+40 \mathrm{mg}$ of zinc $+60 \mu \mathrm{g}$ of selenium) had a significantly higher positive effect on sperm density and overall progressive motility (including fast motility) in comparison with the preparation containing L-carnitine alone [75].

There was a positive association between dietary intake of vitamin $\mathrm{C}$ and semen volume and total motile sperm count in young, healthy university students [59]. Total motile sperm count increased also with higher intakes of lycopene, $\beta$-carotene and cryptoxanthin. Men with poor semen quality, attending fertility clinics, had a significantly lower intake of vitamin $\mathrm{C}$ and lycopene than control subjects [39]. It was demonstrated in subsequent studies that infertile subjects had a significantly lower dietary intake of vitamin $\mathrm{C}$ and $\mathrm{E}$ when compared to the control subjects [76]. In a population of healthy young men, the intake of lycopene was associated with better sperm morphology, and carotenoid intake with higher sperm motility [77]. The authors also observed a nonlinear relationship between vitamin $\mathrm{C}$ intake and sperm concentration. A moderate intake of vitamin $\mathrm{C}$, as well as $\beta$-carotene, was associated with the highest sperm concentration, sperm count, and motile count. Nadjarzadeh et al. confirmed positive correlations between the intake of folate and zinc, and sperm concentration and motility [76]. In a study aiming to evaluate the influence of B vitamins intake on semen parameters of men with MTHFR gene polymorphisms, it was observed that sufficient consumption of folates and vitamin $B_{12}$ improved sperm parameters of men with different MTHFR polymorphisms, especially among men with $\mathrm{T}$ allele of MTHFR C677T polymorphism [78]. Only Minguez-Alarcon et al. did not find an association between the consumption of antioxydants such as $\alpha$-carotene, vitamin E, lutein, zeaxanthin, folate, vitamin $\mathrm{B}_{6}, \mathrm{~B}_{12}$, and sperm parameters [59].

The results of many studies have shown that an adequate intake or supplementation of some antioxidants may be effective in the prevention and treatment of infertility in men. The improvement of pregnancy rate after antioxidant therapy ranged in various studies from $11 \%$ do $41 \%$. Studies that use different combinations of many antioxidant ingredients are particularly promising. The key problem may be choosing the right dose of the supplement $[79,80]$. The improvement of sperm parameters resulting from antioxidant supplementation did not always translate into an improvement in live births or pregnancy rates, indicating the high complexity of this problem.

\section{Caffeine}

Drinking coffee within usual levels of intake (3-4 cups a day) has generally a positive influence on a person's health [81]. However, in higher doses, caffeine may change the Sertoli
Cells glycolytic and oxidative profile, disturbing the male's reproductive potential [82]. In a study conducted among Danish men, increased testosterone levels with increasing caffeine intake was observed, but with no adverse effect on semen quality [83]. Consumption of $>800 \mathrm{mg}$ of caffeine per day resulted in a nonsignificant reduction in semen quality [84]. A meta-analysis conducted in 2017 suggests that caffeine intake may negatively affect male reproductive function, possibly through sperm DNA damage [85]. The authors found that evidence from epidemiological studies on semen parameters and fertility is inconclusive. Karmon et al. did not confirm an association between male caffeine intake and semen quality. They only demonstrated that male caffeine intake was negatively correlated with live birth after assisted reproductive technologies [86].

In most studies, semen parameters were not affected by caffeine intake. However, some authors suggested a negative effect of caffeine-containing beverages on count, concentration and volume of sperm. It is also possible that the less healthy lifestyle of men drinking caffeine-containing soft drinks may explain these findings.

\section{Alcohol}

Studies conducted in earlier years indicated that alcohol consumption changes semen parameters and has an impact on human testicular pathology. It was suggested that these disorders can be associated with hypotestosteronemia, which results from ethanol effects on both the central component of the hypothalamic-pituitary-testicular axis and at the testicular level [87]. These associations have also been confirmed in recent works [88]. Jensen et al. suggest that even modest habitual alcohol consumption of more than 5 units per week had adverse effects on sperm concentration, total sperm count and percentage of spermatozoa with normal morphology [89]. The negative impact of alcohol on the quality of sperm increased with the increase of the amount of alcohol consumed. Men with a typical intake above 40 units/week had a 33\% reduction in sperm concentration compared to men with an intake of 1-5 units in a typical week. Recent alcohol intake (for the week preceding the visit) was linked with an increase in serum testosterone and reduction in sex hormone-binding globulin. Analysis of histological samples from deceased men showed that high alcohol consumption (>80 g alcohol/day) was associated with reduced spermatogenesis, including spermatogenic arrest and Sertoli-cell-only syndrome [90]. There is also biological plausibility to support an increased production of spermatozoa with fragmented or degenerated DNA in association with alcohol abuse. Chronic alcohol use zsignificantly increased the sperm DNA fragmentation index to $49.6 \%$ compared with $33.9 \%$ in nondrinkers [91]. Meta-analysis of cross-sectional studies, which included 
more than 16000 men, confirmed the harmful influence of alcohol consumption on the volume of semen and normal morphology [92]. Alcohol consumption did not consistently have an influence on sperm concentration and its motility though.

Most studies confirm the adverse effect of alcohol on the quality of semen. The negative impact of high alcohol consumption was particularly marked with regard to sperm morphology and DNA damage.

\section{Energy balance}

A lack of balance between the amount of energy consumed and its expenditure and their health consequences, constitute a growing problem in many populations [93]. The effect of obesity on male fertility is thought to be multifactorial. It may be modulated by genetic, endocrinal and environmental influences. Katib explains that male obesity has a negative impact on fertility through direct changes to sperm function and sperm molecular composition, as well as through changes at hormonal levels [94]. Decreased sperm may be a result of changes to the hypothalamic pituitary gonadal axis through reductions in the levels of total testosterone, free testosterone and sex hormone-binding globulin. Moreover, excess adipose tissue causes an increased conversion of testosterone to estradiol, which may be the cause of secondary hypogonadism, through reproductive axis suppression. Infertility in obese men may also be associated with insensitivity to leptin. The increase in leptin levels, characteristic of obesity, contributes to a significant reduction in testosterone production by Leydig cells. Martins et al. also reported that leptin modulates the function of Sertoli cell that are the nutritional support of developing germ cells [95]. The build-up of suprapubic and inner fat may cause scrotal hyperthermia, which is a probable cause of elevated oxidative stress, and may contribute to decreased sperm quality through an influence on mitochondrial dysfunction [96].

Numerous studies have demonstrated that male obesity is related to an increased incidence of low sperm concentration and low progressively motile sperm count. The incidence of oligozoospermia increased proportionally to increasing BMI and was $5.3 \%$ in normal weight men and respectively $9.5 \%$ and $15.6 \%$ in overweight and obese men. Similarly, the prevalence of a low progressively motile sperm count increased with increasing BMI and was respectively $4.5 \%, 8.9 \%$, and $13.3 \%$ in normal weight, overweight and obese men [97]. However, the results of a meta-analysis conducted by MacDonald et al. did not show an association between increased BMI and semen parameters, but there was strong evidence of a negative relationship for testosterone, sex hormone binding globulin and free testosterone with increased BMI [98]. Sermondade et al. confirmed that overweight and obesity significantly increases the risk of oligozoospermia and azoospermia [99]. Subsequently, cross-sectional studies showed that BMI had a marginally significant effect on normal sperm morphology, and that overweight and obese men showed no significantly increased relative risk of abnormal semen parameters. However, in a general male population in Taiwan, sperm concentration showed a significantly negative association with BMI [100]. Moreover, the authors noted an inverse association between BMI, waist-to-height ratio and normal sperm morphology.

Regarding the reproductive hormones, significant negative relationships with BMI were found for total testosterone, free testosterone and sex hormone binding globulin [101]. Ejaculate volume showed a linear decline with increasing BMI and waist circumference in men who did not have fertility problems [102]. Similarly, the total sperm count showed a negative linear association with waist circumference. No significant relationship was seen between BMI or waist circumference and semen concentration, motility, vitality, morphology or DNA fragmentation index. Weight loss during the 14-week intervention involving healthy diet and daily exercise in obese men was associated with an increase in semen volume and total sperm count, as well as an improvement of the reproductive hormonal profile, especially in the group with the largest weight reduction [103]. In one of the studies, in three patients that had undergone bariatric surgery to achieve a drastic decrease in body weight, a significant deterioration of semen parameters was observed [104]. The authors suggest that this effect may be triggered by various mechanisms: the suppression of the deleterious effects of obesity, the negative effect of nutrient deficiency or the release of toxic substances.

The study of Bandel et al. indicated that overweight, per se, was not associated with a higher level of sperm DNA damage [105]. Campbell et al. found that obese men had an increased percentage of sperm with abnormal morphology, low mitochondrial membrane potential and DNA fragmentation. They did not find, however, a significant association between obesity and conventional semen parameters [106]. In a study conducted by Taha et al. fertile obese men had significantly lower sperm concentration, sperm normal morphology, progressive sperm motility, and significantly higher seminal reactive oxygen species and sperm DNA fragmentation, compared with other fertile men [107]. Fariello et al. demonstrated that obesity in men was associated with increased DNA fragmentation and decreased progressive motility and mitochondrial activity [108]. Epigenome and small non-coding RNAs alterations in sperm of obese men were also found to have an impact on male fertility potential [50]. In a study in which 4000 men participated, all semen parameters (sperm morphology, volume, concentration, motility and total motile count) 


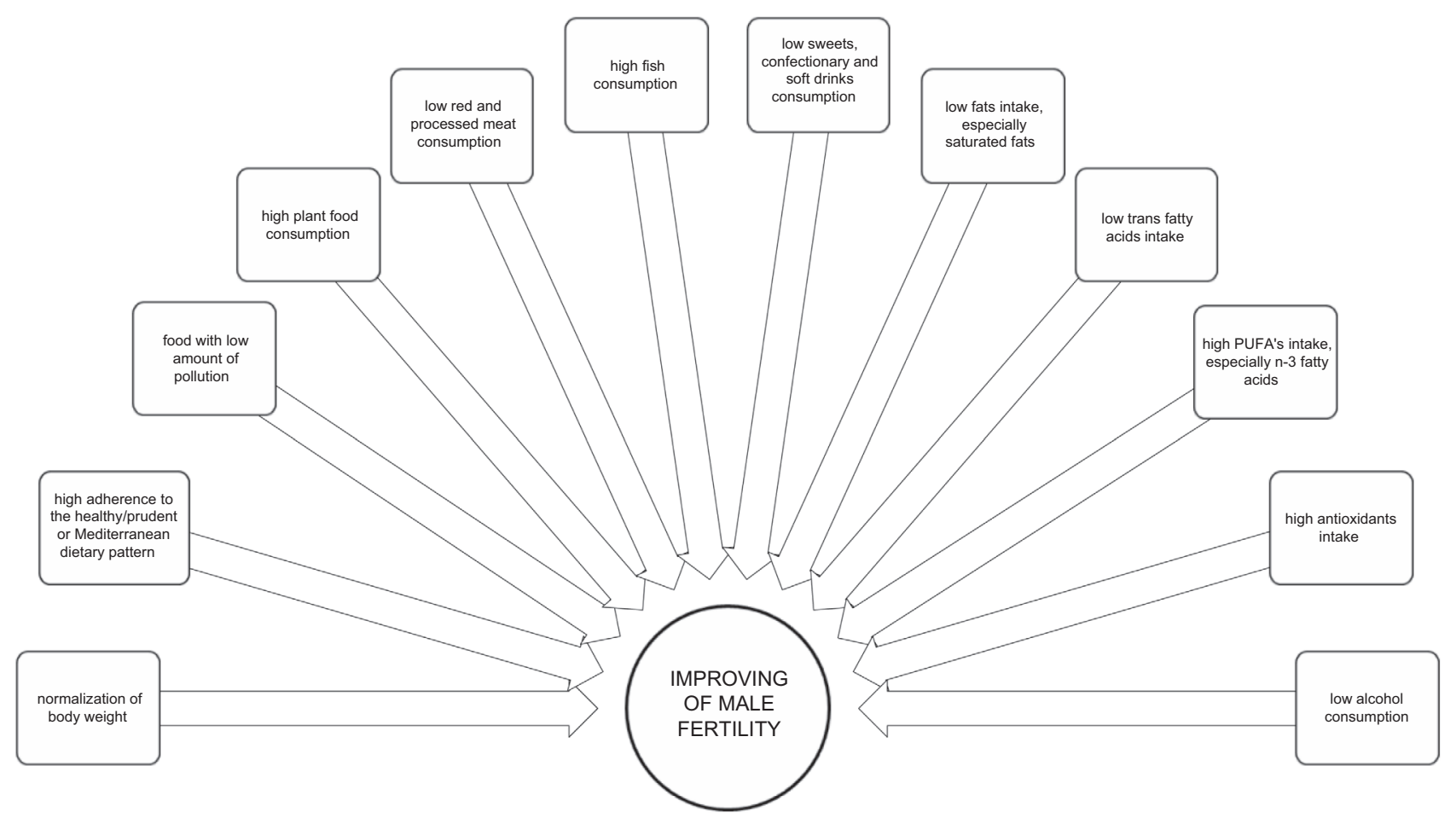

Figure 1. Nutrition-related factors with a beneficial effect on male fertility.

declined with an increasing BMI [109]. The increase in mass was also accompanied by a lowering testosterone concentration and increasing estrogen concentration.

Few studies have included the relationship between mass deficiency and male fertility in their analyzes. Cui et al. showed that men with $\mathrm{BMI}<18.5 \mathrm{~kg} / \mathrm{m}^{2}$ had significantly lower sperm concentration $(59.42 \pm 8.16$ vs. $68.39 \pm$ $8.54 \times 106 / \mathrm{ml})$, progressive motility $(33.62 \pm 11.31 \mathrm{vs}$. $40.28 \pm 12.98 \%$ ), reduced percentage of normal sperm morphology ( $7.63 \pm 1.33$ vs. $12.11 \pm 3.59 \%$ normal), higher testosterone concentration $(398.24 \pm 22.19$ vs. $386.58 \pm$ $21.32 \mathrm{ng} / \mathrm{dl})$, as well as estradiol ( $34.11 \pm 8.27$ vs. $29.32 \pm$ $7.90 \mathrm{pg} / \mathrm{ml}$ ), compared to men with normal BMI [110].

In conclusion, it should be noted that not all older studies confirmed the relationship between excess weight and the quantity and quality of semen. Ambiguous results may have been the result of varied age, lifestyle, as well as the overall health of the surveyed men. In recent years, however, it is increasingly noted that obesity negatively affects the sperm parameters. Studies also showed that weight loss had a positive effect on both sperm morphology and on the percentage of DNA fragmentation index (DFI) [111].

\section{Conclusions}

The results of research conducted over the last 10 years leave no doubt that diet belongs to modifiable factors that can have a significant impact on male fertility (Figure 1). A strong adherence to a healthy dietary pattern, which is based mainly on plant foods, fish and chicken is positively correlated with such indicators as: total sperm count, progressive motility and total motile sperm count, and in some studies also with sperm concentration and morphology. However, attention is drawn to the fact that foods that are considered "healthy" (e.g. fruit, vegetables or fish), can sometimes contain a significant amount of pollution, which negatively affect the parameters of the semen. A high intake of red and processed meat, high fat products and confectionery was associated with poor semen quality in different populations.

The results of research on the influence of individual nutrients confirm the main observations resulting from the analysis of the impact of dietary patterns on the quality of semen: high intake of fats, especially saturated ones, and trans-fatty acids is negatively related to sperm count and concentration. However, the positive effect of polyunsaturated $\mathrm{n}-3$ fatty acids on total sperm count, sperm concentration and a more favorable sperm morphology has been noted. The relationship between the intake of vitamin $\mathrm{D}$ supplements and men's reproductive health is for the time being ambiguous and requires further research.

The phenomenon of infertility in men is particularly strongly related to the occurrence of free radical processes. Studies that have been published in the last 10 years have confirmed that an adequate intake of antioxidants or their 
supplementation have been quite effective in the prevention and treatment of male infertility. Positive results have been reported in the case of a high intake of vitamin C, E, $\beta$-carotene and lycopene supplements, the coenzyme $\mathrm{Q}_{10}$, $\mathrm{N}$-acetyl-cysteine, as well as zinc and selenium. An important problem, however, may be choosing the right dose of the supplement or finding an appropriate combination of antioxidants that may be more effective than any single antioxidant.

Results from epidemiological studies regarding the influence of coffee and beverages that contain caffeine on semen quality and fertility are inconclusive. In most studies, semen parameters were not affected by caffeine intake. Regular consumption of alcohol had adverse effects on sperm concentration, total sperm count, percentage of spermatozoa with normal morphology and increased sperm DNA fragmentation.

Despite some discrepancies in the results of the study, it can also be confirmed that the normalization of men's body weight is beneficial for the quality of sperm and the concentration of male reproductive hormones. Further, long-term studies require the assessment of the impact of drastic weight loss after bariatric surgery on male fertility.

The strength of this work is a comprehensive search of current works, published over the last 10 years, carried out in many electronic databases. However, we cannot exclude that the results obtained by many authors could have been affected by unmeasured confounders, such as physical activity and sedentary behavior, stress, sleep disturbance, occupation, cell phone use and environmental pollution. It is necessary to conduct further, preferably long-term research, as well as carefully designed, placebo-controlled clinical trials to better establish the relationship between diet and fertility in men.

\section{References}

1. Kazem, A., \& Ali, A. (2009) An overview of the epidemiology of primary infertility in Iran. J Reprod Infertil. 10, 213-216.

2. American Society for Reproductive Medicine. (2015) Diagnostic evaluation of the infertile male: a committee opinion. Fertil Steril. 103, 18-25.

3. Zhou, Z., Zheng, D., Wu, H., Li, R., Xu, S., Kang, Y., Cao, Y., Chen, X., Zhu, Y., Xu, S., Chen, Z.J., Mol, B.W., \& Qiao, J. (2018) Epidemiology of infertility in China: a populationbased study. BJOG. 125, 432-441.

4. Vander Borght, M., \& Wyns, C. (2018) Fertility and infertility: definition and epidemiology. Clin Biochem. 16. pii: S00099120(18)30220-0

5. World Health Organization. (2010) WHO laboratory manual for the examination and processing of human semen. http:// whqlibdoc.who.int/publications/2010/9789241547789_eng. pdf (accessed 2.02.2018).

6. Leaver, R.B. (2016) Male infertility: an overview of causes and treatment options. Br J Nurs. 25, 35-40.
7. Houfflyn, S., Matthys, C., \& Soubry, A. (2017) Male obesity: epigenetic origin and effects in sperm and offspring. Curr Mol Biol Rep. 3, 288-296.

8. Evenson, D., \& Wixon, R. (2006) Meta-analysis of sperm DNA fragmentation using the sperm chromatin structure assay. Reprod BioMed Online. 12, 466-472.

9. Witczak, B., Klusek, J.E., \& Klusek, J. (2014) Genetics aspects of male infertility. Medical Studies. 30, 276-279.

10. Wirfält, E., Drake, I., \& Wallström, P. (2013) What do review papers conclude about food and dietary patterns? Food Nutr Res. 57. doi: 10.3402/fnr.v57i0.20523

11. Vujkovic, M., de Vries, J.H., Dohle, G.R., Bonsel, G.J., Lindemans, J., Macklon, N.S., van der Spek, P.J., Steegers, E.A., \& Steegers-Theunissen, R.P. (2009) Associations between dietary patterns and semen quality in men undergoing IVF/ICSI treatment. Hum Reprod. 24, 1304-1312.

12. Gaskins, A.J., Colaci, D.S., Mendiola, J., Swan, S.H., \& Chavarro, J.E. (2012) Dietary patterns and semen quality in young men. Hum Reprod. 27, 2899-2907.

13. Jurewicz, J., Radwan, M., Sobala, W., Radwan, P., Bochenek, M., \& Hanke, W. (2016) Dietary patterns and their relationship with semen quality. Am J Mens Health. 27. pii: 1557988315627139

14. Oostingh, E.C., Steegers-Theunissen, R.P., de Vries, J.H., Lavens, J.S., \& Koster, M.P. (2017) Strong adherence to a healthy dietary pattern is associated with better semen quality, especially in men with poor semen quality. Fertil Steril. 107, 916-923.

15. Liu, C.-Y., Chou, Y.-C., Chao, J.C.-J., Hsu, C.Y., Ha, T.L., \& Tsao, C.W. (2015) The association between dietary patterns and semen quality in a general Asian population of 7282 males. PLoS One. 10, e0134224.

16. Eslamian, G., Amirjannati, N., Rashidkhani, B., Sadeghi, M.R., Baghestani, A.R., \& Hekmatdoost, A. (2016) Adherence to the western pattern is potentially an unfavorable indicator of asthenozoospermia risk: a case-control study. J Am Coll Nutr. 35, 50-58.

17. Cutillas-Tolín, A., Mínguez-Alarcón, L., Mendiola, J., LópezEspín, J.J., Jørgensen, N., Navarrete-Muñoz, E.M., TorresCantero, A.M., \& Chavarro, J.E. (2015) Mediterranean and western dietary patterns are related to markers of testicular function among healthy men. Hum Reprod. 30, 2945-2955.

18. Karayiannis, D., Kontogianni, M.D., Mendorou, C., Douka, L., Mastrominas, M., \& Yiannakouris, N. (2017) Association between adherence to the Mediterranean diet and semen quality parameters in male partners of couples attempting fertility. Hum Reprod. 32, 215-222.

19. Salas-Huetos, A., Bulló, M., \& Salas-Salvadó, J. (2017) Dietary patterns, foods and nutrients in male fertility parameters and fecundability: a systematic review of observational studies. Hum Reprod Update. 23, 371-389.

20. Arab, A., Rafie, N., Mansourian, M., Miraghajani, M., \& Hajianfar, H. (2018) Dietary patterns and semen quality: a systematic review and meta-analysis of observational studies. Andrology. 6, 20-28.

21. Afeiche, M.C., Williams, P.L., Gaskins, A.J., Mendiola, J., Jørgensen, N., Swan, S.H., \& Chavarro, J.E. (2014) Meat intake and reproductive parameters among young men. Epidemiology. 25, 323-330.

22. Eslamian, G., Amirjannati, N., Rashidkhani, B., Sadeghi, M.R., Hekmatdoost, A., Sadeghi, M.R., \& Hekmatdoost, A. (2012) Intake of food groups and idiopathic asthenozoospermia: a case-control study. Hum Reprod. 27, 3328-3336.

23. Afeiche, M.C., Gaskins, A.J., Williams, P.L., Toth, T.L., Wright, D.L., Tanrikut, C., Hauser, R., \& Chavarro, J.E. (2014) Processed meat intake is unfavorably and fish intake 
favorably associated with semen quality indicators among men attending a fertility clinic. J Nutr. 144, 1091-1098.

24. Mínguez-Alarcón, L., Afeiche, M.C., Williams, P.L., Arvizu, M., Tanrikut, C., Amarasiriwardena, C.J., Ford, J.B., Hauser, R., Chavarro, J.E., \& Team, Earth Study (2018) Hair mercury (Hg) levels, fish consumption and semen parameters among men attending a fertility center. Int J Hyg Environ Health. 221, 174-182.

25. Afeiche, M.C., Williams, P.L., Mendiola, J., Gaskins, A.J., Jørgensen, N., Swan, S.H., \& Chavarro, J.E. (2013) Dairy food intake in relation to semen quality and reproductive hormone levels among physically active young men. Hum Reprod. 28, 2265-2275.

26. Maruyama, K., Oshima, T., \& Ohyama, K. (2010) Exposure to exogenous estrogen through intake of commercial milk produced from pregnant cows. Pediatr Int. 52, 33-38.

27. Schaum, J., Schuda, L., Wu, C., Sears, R., Ferrario, J., \& Andrews, K. (2003) A national survey of persistent, bioaccumulative, and toxic (PBT) pollutants in the United States milk supply. J Expo Anal Environ Epidemiol. 13, 177.

28. Rozati, R., Reddy, P.P., Reddanna, P., \& Mujtaba, R. (2002) Role of environmental estrogens in the deterioration of male factor fertility. Fertil Steril. 78, 1187-1194.

29. Meeker, J.D., \& Hauser, R. (2010) Exposure to polychlorinated biphenyls (PCBs) and male reproduction. Syst Biol Reprod Med. 56, 122-131.

30. Martenies, S.E., \& Perry, M.J. (2013) Environmental and occupational pesticide exposure and human sperm parameters: a systematic review. Toxicology. 10, 66-73.

31. Chiu, Y.H., Afeiche, M.C., Gaskins, A.J., Williams, P.L., Petrozza, J.C., Tanrikut, C., Hauser, R., \& Chavarro, J.E. (2015) Fruit and vegetable intake and their pesticide residues in relation to semen quality among men from a fertility clinic. Hum Reprod. 30, 1342-1351.

32. Chiu, Y.H., Gaskins, A.J., Williams, P.L., Mendiola, J., Jørgensen, N., Levine, H., Hauser, R., Swan, S.H., \& Chavarro, J.E. (2015) Intake of fruits and vegetables with low-tomoderate pesticide residues is positively associated with semen-quality parameters among young healthy men. J Nutr. 146, 1084-1092.

33. Robbins, W.A., Xun, L., FitzGerald, L.Z., Esguerra, S., Henning, S.M., \& Carpenter, C.L. (2012) Walnuts improve semen quality in men consuming a western-style diet: randomized control dietary intervention trial. Biol Reprod. 87, 101-108

34. Chavarro, J.E., Toth, T.L., Sonita, M., \& Hauser, R. (2008) Soy food and isoflavone intake in relation to semen quality parameters among men from an infertility clinic. Hum Reprod. 23, 2584-2590.

35. Beaton, L.K., McVeigh, B.L., Dillingham, B.L., Lampe, J.W., \& Duncan, A.M. (2010) Soy protein isolates of varying isoflavone content do not adversely affect semen quality in healthy young men. Fertil Steril. 94, 1717-1722.

36. Hamilton-Reeves, J.M., Vasquez, G., Duval, S.J., Phipps, W. R., Kurzer, M.S., \& Messina, M.J. (2010) Clinical studies show no effects of soy protein or isoflavones on reproductive hormones in men: results of a meta-analysis. Fertil Steril. 94, 997-1007.

37. Heidary, M., Vahhabi, S., Reza Nejadi, J., Delfan, B., Birjandi, M., Kaviani, H., \& Givrad, S. (2008) Effect of saffron on semen parameters of infertile men. Urol J. 5 , 255-259.

38. Safarinejad, M.R., Shafiei, N., \& Safarinejad, S (2011) A prospective double-blind randomized placebo-controlled study of the effect of saffron (Crocus sativus Linn.) on semen parameters and seminal plasma antioxidant capacity in infertile men with idiopathic oligoasthenoteratozoospermia. Phytother Res. 25, 508-516.

39. Mendiola, J., Torres-Cantero, A.M., Vioque, J., Moreno-Grau, J.M., Ten, J., Roca, M., Moreno-Grau, S., \& Bernabeu, R. (2010) A low intake of antioxidant nutrients is associated with poor semen quality in patients attending fertility clinics. Fertil Steril. 93, 1128-1133.

40. Attaman, J.A., Toth, T.L., Furtado, J., Campos, H., Hauser, R., \& Chavarro, J.E. (2012) Dietary fat and semen quality among men attending a fertility clinic. Hum Reprod. 27, $1466-1474$.

41. Jensen, T.K., Heitmann, B.L., Bloomberg Jensen, M., Halldorsson, T.I., Andersson, AM, Skakkebæk, N.E., Joensen, U.N., Lauritsen, M.P., Christiansen, P., Dalgård, C., Lassen, T.H., \& Jørgensen, N. (2013) High dietary intake of saturated fat is associated with reduced semen quality among 701 young Danish men from the general population. Am J Clin Nutr. 97, 411-418.

42. Dadkhah, H., Kazemi, A., Nasr-Isfahani, M.H., \& Ehsanpour, S. (2017) The relationship between the amount of saturated fat intake and semen quality in men. Iran J Nurs Midwifery Res. 22, 46-50.

43. Safarinejad, M.R. (2011) Effect of omega-3 polyunsaturated fatty acid supplementation on semen profile and enzymatic anti-oxidant capacity of seminal plasma in infertile men with idiopathic oligoasthenoteratospermia: a double-blind, placebo-controlled, randomised study. Andrologia. 43, 38-47.

44. Mendeluk, G.R., Cohen, M.I., Ferreri, C., \& Chatgilialoglu, C. (2015) Nutrition and reproductive health: sperm versus erythrocyte lipidomic profile and $\omega$-3 intake. J Nutr Metab. 2015, 670526.

45. Kolahdooz, M., Nasri, S., Modarres, S.Z., Kianbakht, S., \& Huseini, H.F. (2014) Effects of Nigella sativa L. seed oil on abnormal semen quality in infertile men: a randomized, double-blind, placebo-controlled clinical trial. Phytomedicine. 21, 901-905

46. Chavarro, J.E., Mínguez-Alarcón, L., Mendiola, J., CutillasTolín, A., López-Espín, J.J., \& Torres-Cantero, A.M. (2014) Trans fatty acid intake is inversely related to total sperm count in young healthy men. Hum Reprod. 29, 429-440.

47. Rato, L., Alves, M.G., Cavaco, J.E., \& Oliveira, P.F. (2014) High-energy diets: a threat for male fertility? Obes Rev. 15, 996-1007.

48. Esmaeili, V., Shahverdi, A.H., Moghadasian, M.H., \& Alizadeh, A.R. (2015) Dietary fatty acids affect semen quality: a review. Andrology. 3, 450-461.

49. Neto, F.T., Bach, P.V., Najari, B.B., Li, P.S., \& Goldstein, M. (2016) Spermatogenesis in humans and its affecting factors. Semin Cell Dev Biol. 59, 10-26.

50. Raad, G., Hazzouri, M., Bottini, S., Trabucchi, M., Azoury, J., \& Grandjean, V. (2017) Paternal obesity: how bad is it for sperm quality and progeny health? Basic Clin Androl. 27, 20.

51. Minguez-Alarcon, L., Chavarro, J.E., Mendiola, J., Roca, M., Tanrikut, C., Vioque, J., Jørgensen, N., \& Torres-Cantero, A. M. (2017) Fatty acid intake in relation to reproductive hormones and testicular volume among young healthy men. Asian J Androl. 19, 184-190.

52. Chavarro, J.E., Minguez-Alarcon, L., Mendiola, J., CutillasTolín, A., López-Espín, J.J., \& Torres-Cantero, A.M. (2014) Trans fatty acid intake is inversely related to total sperm count in young healthy men. Hum Reprod. 29, 429-440.

53. Bloomberg Jensen, M. (2014) Vitamin D and male reproduction. Nat Rev Endocrinol. 10, 175-186.

54. Boisen, I.M., Hansen, L.B., Mortensen, L.J., Lanske, B., Juul, A., \& Blomberg Jensen, M. (2017) Possible influence 
of vitamin D on male reproduction. J Steroid Biochem Mol Biol. 173, 215-222.

55. Deng, X.L., Li, Y.M., Yang, X.Y., Huang, J.R., Guo, S.L., \& Song, L.M. (2014) Efficacy and safety of vitamin D in the treatment of idiopathic oligoasthenozoospermia. Zhongua Nan Ke Xue. 20, 1082-1085. (Article in Chinese)

56. Blomberg Jensen, M., Lawaetz, J.G., Petersen, J.H., Juul, A., \& Jørgensen, N. (2018) Effects of vitamin D supplementation on semen quality, reproductive hormones, and live birth rate: a randomized clinical trial. Clin Endocrinol Metab. 103, 870-881.

57. Lerchbaum, E., Pilz, S., Trummer, C., Schwetz, V., Pachernegg, O., Heijboer, A.C., \& Obermayer-Pietsch, B. (2017) Vitamin $D$ and testosterone in healthy men: a randomized controlled trial. J Clin Endocrinol Metab. 102, 4292-4302.

58. Canguven, O., Talib, R.A., El Ansari, W., Yassin, D.J., \& Al Naimi, A. (2017) Vitamin D treatment improves levels of sexual hormones, metabolic parameters and erectile function in middle-aged vitamin D deficient men. Aging Male. 20, 9-16.

59. Minguez-Alarcon, L., Mendiola, J, Lopez-Espin, J.J., SarabiaCos, L., Vivero-Salmerón, G., Vioque, J., Navarrete-Muñoz, E. M., \& Torres-Cantero, A.M. (2012) Dietary intake of antioxidant nutrients is associated with semen quality in young university students. Hum Reprod. 27, 2807-2814.

60. Agarwal, A., Gurpriya, Virk G., Ong, C., \& du Plessis, S.S. (2014) Effect of oxidative stress on male reproduction. World J Mens Health. 32, 1-17.

61. Tremellen, K. (2008) Oxidative stress and male infertility - a clinical perspective. Hum Reprod Update. 14, 243-258.

62. Walczak-Jedrzejowska, R., Wolski, J.K., \& SlowikowskaHilczer, J. (2013) The role of oxidative stress and antioxidants in male fertility. Cent European J Urol. 66, 60-67.

63. Showell, M.G., Mackenzie-Proctor, R., Brown, J., Yazdani, A., Stankiewicz, M.T., \& Hart, R.J. (2014) Antioxidants for male subfertility. Cochrane Database Syst Rev. 12, CD007411.

64. Hadwan, M.H., Almashhedy, L.A., \& Alsalman, A.R. (2012) Oral zinc supplementation restores high molecular weight seminal zinc binding protein to normal value in Iraqi infertile men. BMC Urol. 13, 32.

65. Hadwan, M.H., Almashhedy, L.A., \& Alsalman, A.R. (2015) Oral zinc supplementation restores superoxide radical scavengers to normal levels in spermatozoa of Iraqi asthenospermic patients. Int J Vitam Nutr Res. 85, 165-173.

66. Ajina, T., Sallem, A., Haouas, Z., \& Mehdi, M. (2017) Total antioxidant status and lipid peroxidation with and without in vitro zinc supplementation in infertile men. Andrologia. 49, doi: 10.1111/and.12703

67. Moslemi, M.K., \& Tavanbakhsh, S. (2011) Selenium-vitamin E supplementation in infertile men: effects on semen parameters and pregnancy rate. Int J Gen Med. 23, 99-104.

68. Durairajanayagam, D., Agarwal, A., Ong, C., \& Prashast, P. (2014) Lycopene and male infertility. Asian J Androl. 16, 420-425.

69. Devaraj, S., Mathur, S., Basu, A., Aung, H.H., Vasu, V.T., Meyers, S., \& Jialal, I. (2008) A dose response study on the effects of purified lycopene supplementation on biomarkers of oxidative stress. J Am Coll Nutr. 27, 267-73.

70. Safarinejad, M.R. (2012) The effect of coenzyme Q10 supplementation on partner pregnancy rate in infertile men with idiopathic oligoasthenoteratozoospermia: an open-label prospective study. Int Urol Nephrol. 44, 689-700.

71. Lafuente, R., González-Comadrán, M., Solá, I., López, G., Brassesco, M., Carreras, R., \& Checa, M.A. (2013) Coenzyme Q10 and male infertility: a meta-analysis. J Assist Reprod Genet. 30, 1147-1156.
72. Ciftci, H., Verit, A., Savas, M., Yeni, E., \& Erel, O. (2009) Effects of $\mathrm{N}$-acetylcysteine on semen parameters and oxidative/antioxidant status. Urology. 74, 73-76.

73. Safarinejad, M.R., \& Safarinejad, S. (2009) Efficacy of selenium and/or $\mathrm{N}$-acetyl-cysteine for improving semen parameters in infertile men: a double-blind, placebo controlled, randomized study. J Urol. 181, 741-751.

74. Tunc, O., Thompson, J., \& Tremellen, K. (2009) Improvement in sperm DNA quality using an oral antioxidant therapy. Reprod Biomed Online. 18, 761-768.

75. Lipovac, M., Bodner, F., Imhof, M., \& Chedraui, P. (2016) Comparison of the effect of a combination of eight micronutrients versus a standard mono preparation on sperm parameters. Reprod Biol Endocrinol. 14, 84.

76. Nadjarzadeh, A., Mehrsai, A., Mostafavi, E., Gohari, M.R., \& Shidfar, F. (2013) The association between dietary antioxidant intake and semen quality in infertile men. Med J Islam Repub Iran. 27, 204-209.

77. Zareba, P., Colaci, D.S., Afeiche, M., Gaskins, A.J., Jørgensen, N., Mendiola, J., Swan, S.H., \& Chavarro, J.E. (2013) Semen quality in relation to antioxidant intake in a healthy male population. Fertil Steril. 100, 1572-1579.

78. Najafipour, R., Moghbelinejad, S., Aleyasin, A., \& Jalilvand, A. (2017) Effect of B9 and B12 vitamin intake on semen parameters and fertility of men with MTHFR polymorphisms. Andrology. 5, 704-710.

79. Imamovic Kumalic, S., \& Pinter, B. (2014) Review of clinical trials on effects of oral antioxidants on basic semen and other parameters in idiopathic oligoasthenoteratozoospermia. Biomed Res Int. 2014, 426951.

80. Majzoub, A., \& Agarwal, A. (2018) Systematic review of antioxidant types and doses in male infertility: Benefits on semen parameters, advanced sperm function, assisted reproduction and live-birth rate. Arab J Urol. 16, 113-124.

81. Poole, R., Kennedy, O.J., Roderick, P., Fallowfield, J.A., Hayes, P.C., \& Parkes, J. (2017) Coffee consumption and health: umbrella review of meta-analyses of multiple health outcomes. BMJ. 359, j5024.

82. Dias, T.R., Alves, M.G., Bernardino, R.L., Martins, A.D., Moreira, A.C., Silva, J., et al. (2015) Dose-dependent effects of caffeine in human Sertoli cells metabolism and oxidative profile: relevance for male fertility. Toxicology. 328, 12-20.

83. Karmon, A.E., Toth, T.L., Chiu, Y.H., Gaskins, A.J., Tanrikut, C., Wright, D.L., Hauser, R., \& Chavarro, J.E., Earth Study Team. (2017) Male caffeine and alcohol intake in relation to semen parameters and in vitro fertilization outcomes among fertility patients. Andrology. 5, 354-361.

84. Ramlau-Hansen, C.H., Thulstrup, A.M., Bonde, J.P., Olsen, J., \& Bech, B.H. (2008) Semen quality according to prenatal coffee and present caffeine exposure: two decades of follow-up of a pregnancy cohort. Hum Reprod. 23, 2799-2805.

85. Jensen, T.K., Swan, S.H., Skakkebak, N.E., Rasmussen, S., \& Jørgensen, N. (2010) Caffeine intake and semen quality in a population of 2,554 young Danish men. Am J Epidemiol. 171, 883-891.

86. Ricci, E., Viganò, P., Cipriani, S., Somigliana, E., Chiaffarino, F., Bulfoni, A., \& Parazzini, F. (2017) Coffee and caffeine intake and male infertility: a systematic review. Nutr J. 16, 37.

87. La Vignera, S., Condorelli, R.A., Giancarlo Balercia, G., Vicari, E., \& Calogero, A.E. (2013) Does alcohol have any effect on male reproductive function? A review of literature. Asian J Androl. 15, 221-225.

88. Rachdaoui, N., Sarkar, D.K., \& Phil, D. (2017) Pathophysiology of the effects of alcohol abuse on the endocrine system. Alcohol Res. 38, 255-276. 
89. Jensen, T.K., Gottschau, M., Madsen, J.O.B., Andersson, A.M., Lassen, T.H., \& Skakkebæk, N.E. (2014) Habitual alcohol consumption associated with reduced semen quality and changes in reproductive hormones; a cross-sectional study among 1221 young Danish men. BMJ Open. 4, e005462.

90. Pajarinen, J., Karhunen, P.J., Savolainen, V., Lalu, K., Penttilä, A., \& Laippala, P. (1996) Moderate alcohol consumption and disorders of human spermatogenesis. Alcohol Clin Exp Res. 20, 332-337.

91. Komiya, A., Kato, T., Kawauchi, Y., Watanabe, A., \& Fuse, H. (2014) Clinical factors associated with sperm DNA fragmentation in male patients with infertility. Scientific World Journal. 2014, 868303.

92. Ricci, E., Al Betawi, S., Cipriani, S., Candiani, M., Chiaffarino, F., Viganò, P., Noli, S., \& Parazzini, F. (2017) Semen quality and alcohol intake: a systematic review and meta-analysis. Reprod Biomed Online. 43, 38-47.

93. NCD Risk Factor Collaboration (NCD-RisC). (2016) Trends in adult body-mass index in 200 countries from 1975 to 2014: a pooled analysis of 1698 population-based measurement studies with 19.2 million participants. Lancet. 387, 1377-1396.

94. Katib, A. (2015) Mechanisms linking obesity to male infertility. Cent European J Urol. 68, 79-85.

95. Martins, A.D., Moreira, A.C., Sá, R., Monteiro, M.P., Sousa, M., Carvalho, R.A., Silva, B.M., Oliveira, P.F., \& Alves, M.G. (2015) Leptin modulates human Sertoli cells acetate production and glycolytic profile: a novel mechanism of obesity-induced male infertility? Biochim Biophys Acta. 1852, 1824-1832.

96. Palmer, N.O., Bakos, H.W., Fullston, T., \& Lane, M. (2012) Impact of obesity on male fertility, sperm function and molecular composition. Spermatogenesis. 2, 253-263.

97. Hammoud, A.O., Wilde, N., Gibson, M., Parks, A., Carrell, D.T., \& Meikle, A.W. (2008) Male obesity and alteration in sperm parameters. Fertil Steril. 90, 2222-2225.

98. MacDonald, A.A., Herbison, G.P., Showell, M., \& Farquhar, C.M. (2010) The impact of body mass index on semen parameters and reproductive hormones in human males: a systematic review with meta-analysis. Hum Reprod Update. 16, 293-311.

99. Sermondade, N., Faure, C., Fezeu, L., Shayeb, A.G., Bonde, J. P., Jensen, T.K., Van Wely, M., Cao, J., Martini, A.C., Eskandar, M., Chavarro, J.E., Koloszar, S., Twigt, J.M., Ramlau-Hansen, C.H., Borges, E. Jr, Lotti, F., SteegersTheunissen, R.P., Zorn, B., Polotsky, A.J., La Vignera, S., Eskenazi, B., Tremellen, K., Magnusdottir, E.V., Fejes, I., Hercberg, S., Lévy, R., \& Czernichow, S. (2013) BMI in relation to sperm count: an updated systematic review and collaborative meta-analysis. Hum Reprod Update. 19, 221-231.

100. Tsao, C.W., Liu, C.Y., Chou, Y.C., Cha, T.L., Chen, S.C., \& Hsu, C.Y. (2015) Exploration of the association between obesity and semen quality in a 7630 male population. PLOS ONE. 10, e0119458. doi: 10.1371/journal.pone.011945

101. MacDonald, A.A., Stewart, A.W., \& Farquhar, C.M. (2013) Body mass index in relation to semen quality and reproductive hormones in New Zealand men: a cross-sectional study in fertility clinics. Hum Reprod. 28, 3178-3187.

102. Eisenberg, M.L., Kim, S., Chen, Z., Sundaram, R., Schisterman, E.F., \& Buck Louis, G.M. (2014) The relationship between male BMI and waist circumference on semen quality: data from the LIFE study. Hum Reprod. 29, 193-200.

103. Håkonsen, L.B., Thulstrup, A.M., Aggerholm, A.S., Olsen, J., Bonde, J.P., Andersen, C.Y., Bungum, M., Ernst, E.H.,
Hansen, M.L., Ernst, E.H., \& Ramlau-Hansen, C.H. (2011) Does weight loss improve semen quality and reproductive hormones? Results from a cohort of severely obese men. Reprod Health. 8, 24

104. Sermondade, N., Massin, N., Boitrelle, F., Pfeffer, J., Eustache, F., Sifer, C., Czernichow, S., \& Lévy, R. (2012) Sperm parameters and male fertility after bariatric surgery: three case series. Reprod Biomed Online. 24, 206-210.

105. Bandel, I., Bungum, M., Richtoff, J., Malm, J., Axelsson, J., Pedersen, H.S., Ludwicki, J.K., Czaja, K., Hernik, A., Toft, G., Bonde, J.P., Spanò, M., Malm, G., Haugen, T.B., \& Giwercman, A. (2015) No association between body mass index and sperm DNA integrity. Hum Reprod. 30, 1704-1713.

106. Campbell, J.M., Lane, M., Owens, J.A., \& Bakos, H.W. (2015) Paternal obesity negatively affects male fertility and assisted reproduction outcomes: a systematic review and meta-analysis. Reprod Biomed Online. 31, 593-604.

107. Taha, E.A., Sayed, S.K., Gaber, H.D., Abdel Hafez, H.K., Ghandour, N., Zahran, A., \& Mostafa, T. (2016) Does being overweight affect seminal variables in fertile men? Reprod Biomed Online. 33, 703-708.

108. Fariello, R.M., Pariz, J.R., Spaine, D.M., Cedenho, A.P., Bertolla, R.P., \& Fraietta, R. (2012) Association between obesity and alteration of sperm DNA integrity and mitochondrial activity. BJU Int. 110, 863-867.

109. Bieniek, J.M., Kashanian, J.A., Deibert, C.M., Grober, E.D., Lo, K.C., Brannigan, R.E., Sandlow, J.I., \& Jarvi, K.A. (2016) Influence of increasing body mass index on semen and reproductive hormonal parameters in a multi-institutional cohort of subfertile men. Fertil Steril. 106, 1070-1075.

110. Cui, X., Jing, X., Wu, X., \& Yan, M. (2016) Protective effect of resveratrol on spermatozoa function in male infertility induced by excess weight and obesity. Mol Med Rep. 14, 4659-4665.

111. Mir, J., Franken, D., Andrabi, S.W., Ashraf, M., \& Rao, K. (2018) Impact of weight loss on sperm DNA integrity in obese men. Andrologia. Published online: 1 February 2018. doi: 10.1111/and.12957

\section{Acknowledgments}

The project is supported under the program of the Minister Science and Higher Education under the name "Regional Initiative of Excellence" in 2019-2022 project number: 024/RID/2018/19, financing amount: 11.999.000,00PLN.

\section{Authors contribution}

E.S. researched the topic and drafted the review. S.G. provided supervision and critically reviewed the manuscript. All authors contributed to and approved the final version of the manuscript.

\section{Conflicts of interest}

The authors declare no conflicts of interest.

\section{Edyta Suliga}

Al. XI Wieków Kielc 19

25-317 Kielce

Poland

Tel.: +48413496909

edyta.suliga@ujk.edu.pl 